\title{
Irrigation water quality influences heavy metal uptake by willows in
}

\section{biosolids}

W. Scott Laidlaw ${ }^{1}$, Alan J.M. Baker ${ }^{1}$, David Gregory ${ }^{2}$ and Stefan K. Arndt ${ }^{3,4^{*}}$

${ }^{1}$ School of Botany, The University of Melbourne, Parkville, Victoria 3010, Australia.

${ }^{2}$ Technology and Marine Research, Melbourne Water, 990 Latrobe Street, Docklands, Victoria 3008, Australia.

${ }^{3}$ School of Ecosystem and Forest Sciences, The University of Melbourne, 500 Yarra Boulevard, Richmond, Victoria 3121, Australia.

${ }^{4}$ Terrestrial Ecosystem Research, Department of Microbiology and Ecosystem Science, University of Vienna, Althanstrasse 14, 1090 Vienna, Austria

* Corresponding author: Stefan K Arndt.

Phone: (+) 61-90356819

Email: sarndt@unimelb.edu.au 


\section{Abstract}

Phytoextraction is an effective method to remediate heavy metal contaminated landscapes but is often applied for single metal contaminants. Plants used for phytoextraction may not always be able to grow in drier environments without irrigation. This study investigated if willows (Salix $\mathrm{x}$ reichardtii A. Kerner) can be used for phytoextraction of multiple metals in biosolids, an end-product of the wastewater treatment process, and if irrigation with reclaimed and freshwater influences the extraction process. A plantation of willows was established directly onto a tilled stockpile of metal-contaminated biosolids and irrigated with slightly saline reclaimed water $(\mathrm{EC} \sim 2 \mathrm{dS} / \mathrm{cm})$ at a wastewater processing plant in Victoria, Australia. Biomass was harvested annually and analysed for heavy metal content. Phytoextraction of cadmium, copper, nickel and zinc was benchmarked against freshwater irrigated willows. The minimum irrigation rate of $700 \mathrm{~mm}$ per growing season was sufficient for willows to grow and extract metals. Increasing irrigation rates produced no differences in total biomass and also no differences in the extraction of heavy metals. The reclaimed water reduced both the salinity and the acidity of the biosolids significantly within the first 12 months after irrigation commenced and after three seasons the salinity of the biosolids had dropped to $<15 \%$ of initial values. A flushing treatment to remove excess salts was therefore not necessary. Irrigation had an impact on biosolids attributes such as salinity and $\mathrm{pH}$, and that this had an influence on metal extraction. Reclaimed water irrigation reduced the biosolid $\mathrm{pH}$ and this was associated with reductions of the extraction of $\mathrm{Ni}$ and $\mathrm{Zn}$, it did not influence the extraction of $\mathrm{Cu}$ and enhanced the phytoextraction of $\mathrm{Cd}$, which was probably related to the high chloride content of the reclaimed water. Our results demonstrate that flood-irrigation with reclaimed water was a successful treatment to grow willows in a dry climate. However, the reclaimed water can also change biosolids properties, which will influence the effectiveness of willows to extract different metals. 
Keywords: Biosolids, phytoremediation, phytoextraction, irrigation, heavy metal, reclaimed water

\section{Introduction}

Biosolids produced from wastewater treatment are rich in plant nutrients and have gained acceptance as a valuable resource for use as a soil amendment in agriculture, landscaping and mine site rehabilitation (Brisolara and Qi, 2013; Kim and Owens, 2010; McLaughlin et al., 2007). The concentrations of heavy metal contaminants in biosolids can exceed regulatory thresholds precluding re-use of the material for land application (EPA Victoria, 2004). In Australia, the alternative is disposal to a prescribed waste storage facility but this incurs costly levees imposed to encourage industry to reuse, reduce or recycle waste materials (EPA Victoria, 2007). Other remediation options such as chemical treatment and incineration are also costly.

Phytoremediation uses plants to resolve or mitigate contamination issues in the environment. It has been proposed as a cheaper option for remediation of heavy metal contaminants but questions remain concerning the viability and sustainability of this technology (Pilon-Smits and Freeman, 2006; Pinto et al., 2014). Plants can be used to immobilize heavy metal contaminants in a substrate (phytostabilization) so limiting exposure by susceptible biota. However, total metal content will still exceed thresholds regulating reuse. An alternative is phytoextraction, using plants capable of taking up metals to reduce their concentrations in the substrate (Ali et al., 2013; Baker and Brooks, 1989). To be efficient, a phytoextraction system requires plants that are capable of accumulating and concentrating contaminant metals and producing a large, readily harvestable biomass suitable for disposal (Pulford and

Dickinson, 2006; Rascio and Navari-Izzo, 2011). High levels of metal uptake and plant growth need to be sustained as phytoextraction systems typically require several crop cycles 
to achieve remediation goals (Baker, 1981; Van Nevel et al., 2007). Willows (Salix spp.) are one such plant group with the potential for phytoextraction of heavy metals (Greger and Landberg, 1999; Isebrands et al., 2014). Willows have been shown to affect the bioavailability of metals in soil through metal uptake (reducing available metals) and mobilization of metals (Huynh et al., 2010) and can be established and grown successfully in metal-contaminated biosolids when irrigated with freshwater (Laidlaw et al., 2012). However, this is an unsustainable option in areas with restrictions on the use of domestic freshwater, like many cities in Australia.

Treated wastewater, such as that produced at Melbourne Water Corporation's Western Treatment Plant (WTP), has often been under-utilized, discharged to rivers or sea with only a small fraction reclaimed for industrial or domestic purposes. This water is slightly saline $(1.5-2.0 \mathrm{dS} / \mathrm{m})$ and can be reclaimed to support production of woody biomass in a short rotation coppiced system (Dimitriou et al., 2006). Willows have been grown successfully as short rotation coppice for the production of woody biomass and can tolerate salt concentrations higher than the treated wastewater (Hangs et al., 2011). However, the longterm sustainability of using saline irrigation waters on willows is presently unknown. In many parts of the world annual evaporation exceeds annual rainfall. Under these dry conditions plant transpiration and direct evaporation of reclaimed water could increase salinization of the biosolids. The ability of annual rainfall to reduce biosolids salinity is unknown and is likely to be insufficient during periods of below average rainfall. Field and glasshouse trials have shown that salts are readily leached from biosolids with freshwater (Laidlaw et al., 2012). Whilst not as effective as freshwater, the application of moderately saline water can be used to leach excess salts (Ahmed et al., 2007). It is therefore imperative to investigate the extent to which biosolids will become salinized and the effectiveness of the reclaimed water to reduce excess salinity in the biosolids. 
Previous studies established in small field trials that a variety of willow species can be successfully grown directly in biosolids when irrigated with freshwater. The main aim of this study was to test on an industrial scale if irrigation of willow trees with reclaimed water is a sustainable way of growing willow trees for phytoremediation of heavy metal contaminated biosolids. Our specific objectives were to investigate: a) if water quality influences the metal extraction and biomass production of willows (comparison reclaimed $v s$ freshwater); $\mathrm{b}$ ) if a greater amount of flood irrigation lead to an increased biomass production and the phytoextraction of contaminant metals; and c) if the flood irrigation changed the properties of biosolids (especially salinity and $\mathrm{pH}$ ) and had an influence on metal extraction.

\section{Material and methods}

\subsection{Field Site}

The field site for this study was located at the Melbourne Water Corporation operated Western Treatment Plant, Werribee, Victoria, Australia (37 $59^{\prime} 36^{\prime \prime}$ S, $144^{\circ} 36^{\prime} 56^{\prime \prime}$ E). The WTP covers approximately 11,000 ha and some $18 \%$ of the flow and $48 \%$ of biochemical oxygen demand (BOD) is contributed by trade waste sources. Past external activities resulted in a significant metal loading at the sewage treatment plant and the majority of this metal loading is retained within the biosolids that were stored on site. The field site was adjacent to a sewage treatment lagoon and was enclosed by a netting fence to exclude sheep, cattle and rabbits. The site was an earth bund storage pan $(40 \mathrm{~m}$ x $90 \mathrm{~m})$ containing a layer of biosolids over soil. The biosolids were produced by air-drying sludge extracted from the adjacent wastewater treatment lagoons (prior to 2003) resulting in a hard, deeply fissured layer 0.3 to $0.4 \mathrm{~m}$ thick. In June 2008 the biosolids were ripped and graded and then tilled with a disc plough. The tilled biosolids were acidic ( $\mathrm{pH} 4.6$ ) and moderately saline (EC $3.7 \mathrm{mS} \mathrm{cm}^{-1}$ ) (supplementary data). The oven-dry bulk density of the tilled biosolids was $0.47 \mathrm{~g} \mathrm{~cm}^{-3}$. 


\subsection{Climate}

Long-term mean annual rainfall and evaporation and temperature data for the region west of Melbourne were obtained from the Laverton RAAF weather station $\left(37.86^{\circ} \mathrm{S} 144.76^{\circ}\right.$ E) located approximately $19 \mathrm{~km}$ north east of the Western Treatment Plant (WTP), Werribee and Avalon Airport, Victoria $\left(38.03^{\circ} \mathrm{S}, 144.48^{\circ} \mathrm{E}\right)$, approximately $10 \mathrm{~km}$ west from WTP (Bureau of Meteorology, 2012).

\subsection{Construction and set-up of trial.}

The field trial was constructed to compare water quality, different rates of irrigation and management of salinity. We constructed four large blocks $(10 \times 40 \mathrm{~m})$ and one small block $(10 \times 13 \mathrm{~m})$ that were filled with tilled biosolids $(50 \mathrm{~cm}$ depth). The all blocks were planted with Salix x reichardtii A. Kerner and the four large blocks were flood irrigated with reclaimed water, whilst the small block was drip irrigated with freshwater (potable water). The large blocks received different amounts of flood irrigation, namely $700 \mathrm{~mm}$ (LIF), 1200 $\mathrm{mm}$ (MIF), and $2000 \mathrm{~mm}$ (HIF) in total during the growing seasons and all of these blocks were flushed during winter. The remaining of the large blocks received the medium amount of flood irrigation, but was not flushed during winter (MI). An area of tilled biosolids adjacent to the treatment blocks was keep free of plant cover and did not receive any irrigation. This area (NI) was used to monitor the chemical properties of the biosolids overtime. The biosolids present a mixture of differently aged biosolids; the tilling prior to the filling of the treatment blocks ensured that biosolids were well-mixed and relative uniform prior to treatment start.

The blocks were separated with clay check banks and a $1 \mathrm{~mm}$ thick polyethylene membrane was incorporated in the centre of each bank to reduce lateral movement of irrigation water. A diesel powered water pump was located on the bank of the adjacent lagoon to transfer reclaimed water (Class C water: $\mathrm{pH} 6-9$, BOD $<20 \mathrm{mg} \mathrm{L}^{-1}$, TSS $<30 \mathrm{mg} \mathrm{L}^{-}$ 
1, E. coli $<1000$ organisms $/ 100 \mathrm{~mL})($ EPA Victoria, 2003) to the blocks via $100 \mathrm{~mm}$ PVC piping. The inlet to each treatment block was fitted with manual valves so that each block could be flooded as required. The small block was irrigated with freshwater (FW) via drip irrigation hosing $\left(2.4 \mathrm{~L} \mathrm{hr}^{-1}\right)$ controlled by a battery powered timer (Gardena T1030). One large block (MF) and the FW treatment block had no drainage. The remaining large blocks (LIF, MIF, HIF) had rock-filled trenches installed across the end of each block $0.4 \mathrm{~m}$ below the surface of the biosolids. A screw-capped pipe attached to each trench allowed each block to be manually drained during winter.

\subsection{Planting}

Cuttings of Salix $\mathrm{x}$ reichardtii that each were $25 \mathrm{~cm}$ long were planted in five double rows in each treatment block of biosolids. All cuttings were pre-soaked in water for 24 to 48 hours prior to planting. Cuttings were planted $0.5 \mathrm{~m}$ a part (equivalent to 21,000 plants $\mathrm{ha}^{-1}$ ) in hand-made holes leaving 3-4 $\mathrm{cm}$ of stem above ground surface. Irrigation channels 100 mm deep were excavated within each double row of willows to enhance lateral surface flow of irrigation water. Each channel was supplied with water through a v-notch weir so that irrigation water was distributed evenly across each block. Channels were cleaned out at the start of growing season (October). Dead willows were replaced with new cuttings in early spring 2009 and 2010.

\subsection{Irrigation}

Complete flooding of each treatment block delivered approximately $150 \mathrm{~mm}$ of water and each block was flooded multiple times during the growing season. In the first growing season (October-March) all blocks were irrigated at the same rate, each receiving a total of $1000 \mathrm{~mm}$ of water over 6 months. In the second and third years one block, a low irrigation 
treatment (LIF) received a total irrigation of $700 \mathrm{~mm}$, the high irrigation treatment block (HIF) received a total of $2000 \mathrm{~mm}$ and the remaining blocks (MIF, MI, FW) received 1200 $\mathrm{mm}$ in total during the growing seasons.

\subsubsection{Mid-winter leaching}

In the winters of 2009 and 2010 the drains in blocks LIF, MIF and HIF were opened, the blocks flooded to capacity and allowed to drain out to reduce potential salt build up in the biosolids. In winter 2011 all blocks were opened to allow drainage and a single block (MIF) was flooded to capacity with reclaimed water. Samples of the reclaimed water used for flushing and the water flowing out of the drainpipes were collected. All water samples were measured for acidity using a Mettler-Toledo SevenMulti fitted with InLab Expert Pro pH probe calibrated with $\mathrm{pH} 4$ and $\mathrm{pH} 7$ buffers. The electric conductivity of the water samples was measured as an indicator of salinity using a Mettler-Toledo SevenMulti fitted with InLab 730 conductivity probe calibrated against a $1.413 \mathrm{mS} \mathrm{cm}^{-1}$ standard.

\subsection{Biomass harvesting and sampling}

The blocks of willows were harvested annually (three times) during this study. In the first year stems were harvested in mid-winter (July) and in years 2 and 3 stems with leaves were harvested in mid-autumn (March/April). At harvest, all plants in each block were cut at approximately $50 \mathrm{~mm}$ above ground level. Eighteen plants from each of 5 sub-blocks within each treatment block were collected and a fresh weight for each plant was recorded using battery-powered scales $(30 \pm 0.05 \mathrm{~kg})$ in the field. Eighteen stems (from separate plants) were retained from each sub-block to estimate the weight ratio of leaves to stem in the plants and to estimate the fresh to oven-dry weight ratio. Leaves were removed from the stems and a fresh weight for the sampled stems and leaves was recorded in the field on battery-powered scales. 
All samples were then oven-dried to constant weight at $60^{\circ} \mathrm{C}$ for 7 to 10 days. The fresh weight of plant material harvested in each block was multiplied by the ratio of dry weight to fresh weight to estimate the biomass in the field as oven-dry (OD) $\mathrm{t} \mathrm{ha}^{-1}$. The proportions of oven-dry leaves and oven-dry stems were multiplied by the estimated oven-dry field biomass to determine the mass of OD leaf material per ha and the mass of OD stem material ha ${ }^{-1}$. All harvested material was removed from the trial site each year.

\subsection{Physical and chemical analysis of biosolids}

Ten samples of biosolids $(0-100 \mathrm{~mm})$ were collected every six months from the side of the central irrigation channel in each flooded block (MI, LIF, MIF, HIF), from beneath drippers in the freshwater block (FW) and from a non-irrigated area (NI) adjacent to the treatment blocks. These samples were analysed for acidity $(\mathrm{pH})$ and electrical conductivity. To analyse these parameters in different depths of biosolids we collected volumetric samples in different depths in 2009 and 2011 of the MIF and the NI treatment. Samples were taken at $0-0.1,0.1-0.2,0.2-0.3,0.3-0.4,0.4-0.5,0.5-0.6 \mathrm{~m}$ depth and then oven-dried $\left(60{ }^{\circ} \mathrm{C}\right)$ to constant weight to determine bulk density. The biosolids were oven-dried at $40{ }^{\circ} \mathrm{C}$ for 2 days and then sieved through a $2 \mathrm{~mm}$ mesh brass sieve. The acidity of the biosolids was measured in a substrate and water mix (1:5) using a Mettler-Toledo SevenMulti fitted with InLab Expert Pro $\mathrm{pH}$ probe calibrated with $\mathrm{pH} 4$ and $\mathrm{pH} 7$ buffers. The electrical conductivity of the substrate and water slurry was measured as an indicator of salinity using a Mettler-Toledo SevenMulti fitted with InLab 730 conductivity probe calibrated against a $1.413 \mathrm{mS} \mathrm{cm}$ standard.

The total concentrations of macro/micro nutrients and contaminant metals/metalloids present in the biosolids were determined by acid digestion followed by ICP-AES. These samples were only analyzed in the NI treatment. Samples $(\sim 0.2 \mathrm{~g})$ were weighed into $50 \mathrm{~mL}$ 
glass digestion tubes and $6 \mathrm{~mL}$ of reverse aqua regia $\left(3: 1 \mathrm{HNO}_{3}: \mathrm{HCl}\right)$ was added to each tube. Two blank tubes (no biosolids) were included in each rack to estimate background metal contamination in the digestion procedure. Digestion tubes were left in a fume cupboard for approximately 12 hours overnight at room temperature. The following day the tubes were heated to $115{ }^{\circ} \mathrm{C}$ for 4 hours and shaken lightly once every hour. After 4 hours hydrogen peroxide $(2 \mathrm{~mL})$ was added to each tube and the samples were heated at $115^{\circ} \mathrm{C}$ for a further 20 minutes. The tubes were then allowed to cool and diluted with deionised water to $50 \mathrm{~mL}$. All tubes were sealed with Parafilm ${ }^{\circledR}$ and mixed by inversion three times. An aliquot of each sample was transferred to $10 \mathrm{~mL}$ disposable polypropylene centrifuge tubes for analysis by ICP-AES (Varian Vista Pro Axial, Varian AUS Pty Ltd).

The available / exchangeable metal pool of the biosolids was determined by extraction with a magnesium chloride solution. Eight $g$ of dry biosolids were shaken with $40 \mathrm{~mL}$ of a $1 \mathrm{M}$ magnesium chloride solution $(\mathrm{pH} 7)$ at room temperature for 2 hrs. Extraction tubes were centrifuged and a sample of the supernatant was taken for element analysis by ICP-AES.

Soil and biosolids were assessed for total $\mathrm{C}$ and $\mathrm{N}$ content using an elemental analyser (EuroEA 3028HT; EuroVector SpA, Milan, Italy) connected to a gas isotope ratio mass spectrometer (IsoPrime; GV Instruments, Manchester, UK)(Livesley et al., 2009).

\subsection{Chemical analysis of biomass}

During each harvest subsamples of leaves (5 - $40 \mathrm{~g}$ fresh weight) and stem (100-150 $\mathrm{mm}$ ) were collected from the vertical centre of each harvested plant. The subsamples from each treatment block were combined, with leaves and stems processed separately. Leaf and stem samples were washed in a dilute solution of Triton $\mathrm{X}$ and rinsed three times in deionized water to remove surface contamination by soil or biosolids. Stems were cut into $5 \mathrm{~mm}$ pieces. All plant materials were oven-dried at $60{ }^{\circ} \mathrm{C}$ for 4 days, ground up in an ultra-centrifugal rotor 
mill (Model ZM200, Retsch GmbH, Haan, Germany) then re-dried at $60{ }^{\circ} \mathrm{C}$. Dry ground plant material was weighed $(0.2 \mathrm{~g})$ and placed into $50 \mathrm{~mL}$ glass digestion tubes and $5 \mathrm{~mL}$ of concentrated nitric acid (69\%) was added to each tube and digested as outlined above. Two blank tubes (no plant material) were included with each batch of tubes to estimate background metal contamination in the digestion procedure. Two tubes containing a reference material of Salix leaves were included in each digest batch to monitor any batch-to-batch variations. An aliquot of each digestate was transferred to $10 \mathrm{~mL}$ disposable polypropylene centrifuge tubes for analysis by ICP-AES. Digestate samples were analysed in conjunction with analytical standards made from certified stock solutions (High Purity Standards Pty Ltd, USA). A 5\% nitric acid solution was used to prepare all ICP-AES standards and as a standard blank. The method detection limits by ICP-AES for the elements of interest in $\mathrm{mg} \mathrm{kg}^{-1}$ of oven-dry material were As 8.76, Cd 0.08, Cr 0.12, Cu 0.15, Hg 1.76, Ni 0.63 and Zn 0.35.

\subsection{Biomass metal extraction rates}

The amount of metal removed from the field site by harvesting above-ground biomass was calculated by multiplying the metal content of oven dry plant material $\left(\mathrm{mg} \mathrm{kg}^{-1}\right)$ by the oven dry biomass $\left(\mathrm{t} \mathrm{ha}^{-1}\right)$ harvested in each block. The metal mass extracted in leaves and stems was calculated separately then combined to produce total extracted metal $\left(\mathrm{g} \mathrm{ha}^{-1}\right)$ in total harvested plant material.

\subsection{Statistics}

Statistical tests were applied to the data to address the three research questions raised in this study. The impact of irrigation with reclaimed water on biosolids acidity and salinity was assessed by comparing means (Students t-test, IBM SPSS Statistics 20) between the nonirrigated biosolids (NI) and the medium irrigation treatment (MI). The impact of water 
quality on biosolids salinity and acidity, biomass production and metal extraction was assessed by comparing means (Students t-test, IBM SPSS Statistics 20) between the fresh water treatment (FW) and the medium irrigation treatment (MI). The impact of additional winter flooding on biosolids salinity and acidity, biomass production and metal extraction was assessed by comparing means (Students t-test, IBM SPSS Statistics 20) between the medium irrigation and flush treatment (MIF) and the medium irrigation treatment (MI). The impact of the three irrigation rates on biosolids salinity and acidity, biomass production and metal extraction was assessed by testing for differences between the three treatment blocks (LIF, MIF and HIF) using one-way ANOVA (IBM SPSS Statistics 20). Changes in biosolids salinity and acidity, biomass production and metal extraction within each treatment and between seasons were tested using one-way ANOVA (IBM SPSS Statistics 20). Homogeneity of variances was tested using Levene's statistic and post hoc comparisons between groups were made using LSD for equal variances and Dunnett's T3 for unequal variances.

\section{Results}

\subsection{Climate}

For the first two years of the field trial annual rainfall was less than the long-term mean of around $480 \mathrm{~mm}$ per year and annual evaporation was greater than the long-term mean (supplementary data). In the third year rainfall was almost double the long-term mean (973 $\mathrm{mm}$ ) and evaporation was less than the long-term mean. The third growing season of the trial (2010/11) was cooler with fewer days where the daily minimum temperature exceeded $10^{\circ} \mathrm{C}$ compared to the previous two seasons. There were also fewer days where the maximum daily temperature exceeded $21^{\circ} \mathrm{C}$, especially in Feb/Mar 2011 (supplementary data). 


\subsection{Reclaimed Water}

The reclaimed water used for irrigation of the willows was slightly alkaline with a mean $\mathrm{pH}$ of 7.6 (supplementary data). Conductivity of the reclaimed water was higher than freshwater and fluctuated seasonally ranging from $1.6 \mathrm{mS} \mathrm{cm} \mathrm{cm}^{-1}$ in winter to $2.0 \mathrm{mS} \mathrm{cm}^{-1}$ in summer (Melbourne Water Corporation, unpublished data). Sodium was the main cation present (285 $\mathrm{mg} / \mathrm{L}$ ) with $\mathrm{K}, \mathrm{Ca}$ and $\mathrm{Mg}$ an order of magnitude less. Manganese, $\mathrm{Zn}$ and $\mathrm{Cu}$ were the predominant trace metals.

\subsection{Irrigation with Reclaimed Water}

The acidity of biosolids that were subject to natural rainfall and not irrigated with reclaimed water (NI) showed changes of $<0.5 \mathrm{pH}$ units over the period of the field trial (Fig. 1). The salinity of these biosolids showed a significant $30 \%$ decrease by the end of the trial (Fig. 1). In contrast, the areas of biosolids irrigated with either reclaimed water or freshwater had significantly larger decreases in acidity and salinity compared to the non-irrigated biosolids (Fig. 1, Table 1). At the end of the field trial the acidity of the irrigated biosolids had decreased by more than one $\mathrm{pH}$ unit and the salinity had decreased from $2.5 \mathrm{mS} \mathrm{cm}^{-1}$ to $<1$ $\mathrm{mS} \mathrm{cm}{ }^{-1}$ in all irrigation treatments (Fig. 1). 

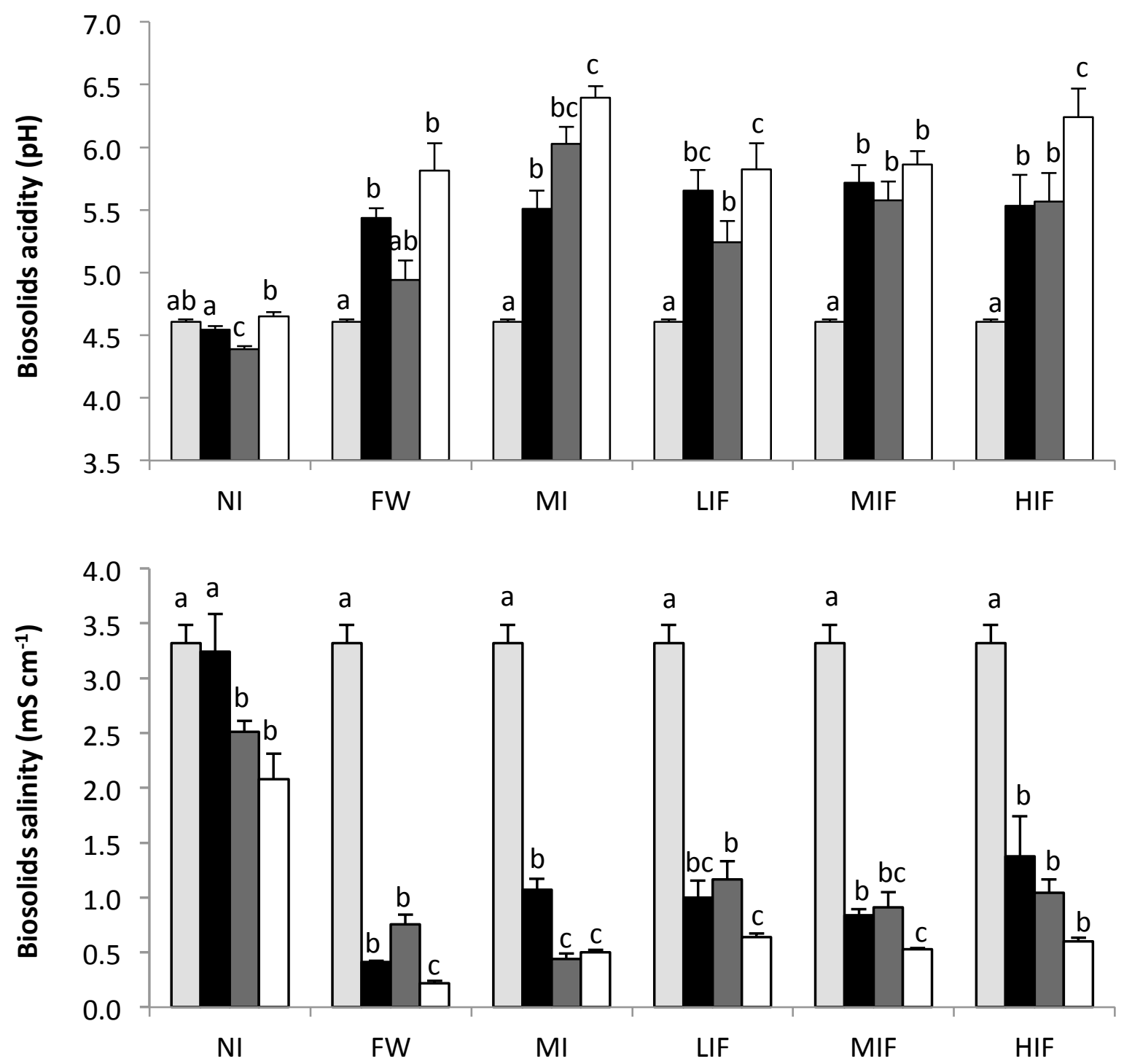

Figure 1 The acidity (upper panel, $\mathrm{pH}$ ) and electrical conductance (lower panel, $\mathrm{mS} \mathrm{cm}^{-1}$ ) of untilled biosolids (light grey) and tilled biosolids from within the five treatment groups. Biosolids were sampled from treatment blocks in May 2009 (black), May 2010 (grey) and May 2011 (open). Treatment groups are non-irrigated (NI), fresh water, drip-irrigated (FW), reclaimed water, flood irrigated at medium rate with no mid-winter flush (MI), low (LIF), medium (MIF) and high flood irrigation rate with a mid-winter flush irrigation (HIF). Different letters indicate statistically significant differences between different sampling times within each treatment group; error bars are standard error of the mean. Additional statistical tests of differences between treatments are listed in Table 1. 
Table 1 Statistics for between-treatment comparison of means of biosolids acidity, biosolids salinity, willow biomass and extracted metal mass. Pairs of means were compared by Students $t$-test and multiple means were tested by one-way ANOVA.

\section{Between Treatment Comparisons}

Impact of irrigation. No Irrigation (NI) vs Medium Irrigation (MI)

\begin{tabular}{lrrrrrr} 
& 2009 & & 2010 & & 2011 & $* * *$ \\
Acidity (pH) & $\mathrm{t}=-6.677$ & $* *$ & $\mathrm{t}=-11.809$ & $* * *$ & $\mathrm{t}=-17.596$ & $* * *$ \\
Salinity (EC) & $\mathrm{t}=6.087$ & $* * *$ & $\mathrm{t}=18.736$ & $* * *$ & $\mathrm{t}=6.816$ & $* *$ \\
\hline
\end{tabular}

Water quality. Freshwater (FW) vs Medium Irrigation (MI)

Acidity $(\mathrm{pH})$

Salinity (EC)

Biomass

Cd extraction

$\mathrm{Cu}$ extraction

Ni extraction

Zn extraction

$$
\begin{array}{ll}
\mathrm{t}=-0.458 \quad \mathrm{~ns} & \mathrm{t}=-5.284 \\
\mathrm{t}=-6.452 \quad * * * & \mathrm{t}=3.066 \\
& \\
& \mathrm{t}=4.525 \\
& \mathrm{t}=1.502 \\
& \mathrm{t}=2.602 \\
& \mathrm{t}=3.700 \\
& \mathrm{t}=4.512
\end{array}
$$

Winter flushing of salts. Medium irrigation (MI) vs Medium irrigation flushed (MIF)

Acidity $(\mathrm{pH})$

Salinity (EC)

Biomass

Cd extraction

$\mathrm{Cu}$ extraction

$\mathrm{Ni}$ extraction

Zn extraction

$$
\begin{aligned}
& t=-1.042 \\
& t=2.023
\end{aligned}
$$

$\mathrm{t}=2.204$

$\mathrm{t}=-3.171$

$\mathrm{t}=2.484$

$\mathrm{t}=0.846$

$\mathrm{t}=2.091$

$\mathrm{t}=1.198$

$\mathrm{t}=-0.235$

$\mathrm{ns}$
$*$
$*$
$\mathrm{~ns}$
$\mathrm{~ns}$
$\mathrm{~ns}$
$\mathrm{~ns}$

ns $\quad \mathrm{t}=3.816$

$\mathrm{t}=-0.970$

$\mathrm{t}=0.453$

$t=-0.583$

$\mathrm{t}=0.105$

$\mathrm{t}=0.138$

$t=-0.569$
**

ns

ns

ns

ns

ns

ns

Irrigation rate. Low (LIF) vs Medium (MIF) vs High (HIF)

$\begin{array}{lllllll}\text { Acidity (pH) } & \mathrm{F}=0.251 & \mathrm{~ns} & \mathrm{~F}=1.056 & \mathrm{~ns} & \mathrm{~F}=1.470 & \mathrm{~ns} \\ \text { Salinity (EC) } & \mathrm{F}=1.448 & \mathrm{~ns} & \mathrm{~F}=0.796 & \mathrm{~ns} & \mathrm{~F}=3.595 & \mathrm{~ns} \\ \text { Biomass } & & & \mathrm{F}=0.470 & \mathrm{~ns} & \mathrm{~F}=1.573 & \mathrm{~ns} \\ \text { Cd extraction } & & & \mathrm{F}=1.630 & \mathrm{~ns} & \mathrm{~F}=2.275 & \mathrm{~ns} \\ \text { Cu extraction } & & & \mathrm{F}=1.247 & \mathrm{~ns} & \mathrm{~F}=0.560 & \mathrm{~ns} \\ \text { Ni extraction } & & \mathrm{F}=3.127 & \mathrm{~ns} & \mathrm{~F}=2.872 & \mathrm{~ns} \\ \text { Zn extraction } & & \mathrm{F}=1.285 & \mathrm{~ns} & \mathrm{~F}=0.485 & \mathrm{~ns}\end{array}$

\section{Between Season Comparisons}

Untilled vs May'09 vs May'10 vs Mar'11

No Irrigation

Freshwater

Medium Irrigation

Low irrigation + winter flush

Medium irrigation + winter flush

High irrigation + winter flush

$\begin{array}{rl}\text { Acidity }(\mathrm{pH}) & \\ \mathrm{F}=18.71 & * * * \\ \mathrm{~F}=14.71 & * * * \\ \mathrm{~F}=50.43 & * * * \\ \mathrm{~F}=11.80 & * * * \\ \mathrm{~F}=24.06 & * * * \\ \mathrm{~F}=10.90 & * * *\end{array}$

Salinity (EC)

$\mathrm{F}=6.894$

$\mathrm{F}=237.9$

$\mathrm{F}=183.1$

$\mathrm{F}=74.88$

$\mathrm{F}=135.1$

$\mathrm{F}=32.91$ 
Table 2 Acidity (pH) and salinity (EC) of biosolids (B) and soil (S) sampled at six depths $(\mathrm{cm})$ in the trial block receiving medium irrigation rate and a winter flush (MIF) and in the block of non-irrigated biosolids (NI) at the end of the first year (Sept 2009) and end of the experiment (July and Sept 2011). NI samples $n=6$. MIF samples $n=1$.

\begin{tabular}{|c|c|c|c|c|c|c|c|}
\hline \multicolumn{2}{|l|}{ Depth } & \multirow{2}{*}{$\begin{array}{c}\text { MIF } \\
\text { Sep ‘09 } \\
\text { pH }\end{array}$} & \multirow{2}{*}{$\begin{array}{c}\text { MIF } \\
\text { Jul'11 } \\
\text { pH }\end{array}$} & \multirow{2}{*}{$\begin{array}{c}\text { NI } \\
\text { Dec '11 } \\
\text { pH }\end{array}$} & \multirow{2}{*}{$\begin{array}{c}\text { MIF } \\
\text { Sep '09 } \\
\mathrm{mS} \mathrm{cm}^{-1}\end{array}$} & \multirow{2}{*}{$\begin{array}{c}\text { MIF } \\
\text { Jul '11 } \\
\mathrm{mS} \mathrm{cm}^{-1}\end{array}$} & \multirow{2}{*}{$\begin{array}{c}\text { NI } \\
\operatorname{Dec}^{'} 11 \\
\mathrm{mS} \mathrm{cm}^{-1}\end{array}$} \\
\hline $\mathrm{cm}$ & & & & & & & \\
\hline $0-6$ & B & 4.79 & 6.50 & 4.67 & 2.02 & 0.44 & 0.96 \\
\hline $10-16$ & B & 4.74 & 6.44 & 4.37 & 1.30 & 0.52 & 2.49 \\
\hline $20-26$ & B & 4.82 & 6.02 & 4.36 & 1.06 & 0.48 & 2.77 \\
\hline $30-36$ & B & 4.87 & 5.47 & - & 1.37 & 0.23 & - \\
\hline $40-46$ & $B \& S$ & 4.80 & 5.46 & - & 0.61 & 0.19 & - \\
\hline $50-56$ & $\mathrm{~S}$ & 5.11 & - & - & 0.26 & - & - \\
\hline
\end{tabular}

Table 3 Total concentration ( $\mathrm{mg} \mathrm{kg}^{-1}$ ) and $\mathrm{MgCl}_{2}$ extractable concentration $\left(\mathrm{mg} \mathrm{kg}^{-1}\right)$ of Cd, $\mathrm{Cu}, \mathrm{Ni}$ and $\mathrm{Zn}$, electrical conductivity and acidity in non-irrigated biosolids $(0-10 \mathrm{~cm})$ collected in year 1 and year 3 . Error values are standard deviations, $n=10$. Concentrations were compared between years by t-test $(*=\mathrm{p}<0.05, * *=\mathrm{p}<0.01)$.

\begin{tabular}{lllrlrll}
\hline & & & 2009 & 2011 & $t$-test \\
\hline $\mathrm{Cd}$ & Total & $\mathrm{mg} \mathrm{kg}^{-1}$ & 23 & \pm 3 & 22 & \pm 3 & .s. \\
& Extractable & $\mathrm{mg} \mathrm{kg}^{-1}$ & 11 & \pm 1 & 3 & \pm 1 & $* *$ \\
$\mathrm{Cu}$ & Total & $\mathrm{mg} \mathrm{kg}^{-1}$ & 774 & \pm 99 & 774 & \pm 89 & n.s. \\
& Extractable & $\mathrm{mg} \mathrm{kg}^{-1}$ & 4 & \pm 0.4 & 1 & \pm 0.3 & $* *$ \\
$\mathrm{Ni}$ & Total & $\mathrm{mg} \mathrm{kg}^{-1}$ & 198 & \pm 21 & 129 & \pm 21 & $* *$ \\
& Extractable & $\mathrm{mg} \mathrm{kg}^{-1}$ & 58 & \pm 9 & 17 & \pm 5 & $* *$ \\
$\mathrm{Zn}$ & Total & $\mathrm{mg} \mathrm{kg}^{-1}$ & 1569 & \pm 196 & 1025 & \pm 226 & $* *$ \\
& Extractable & $\mathrm{mg} \mathrm{kg}^{-1}$ & 721 & \pm 99 & 207 & \pm 64 & $* *$ \\
\hline $\mathrm{EC}$ & & $\mathrm{mS} \mathrm{cm}^{-1}$ & 3.69 & \pm 0.16 & 2.16 & \pm 0.49 & $* *$ \\
$\mathrm{pH}$ & & 4.59 & \pm 0.13 & 4.67 & \pm 0.08 & $*$ \\
\hline
\end{tabular}




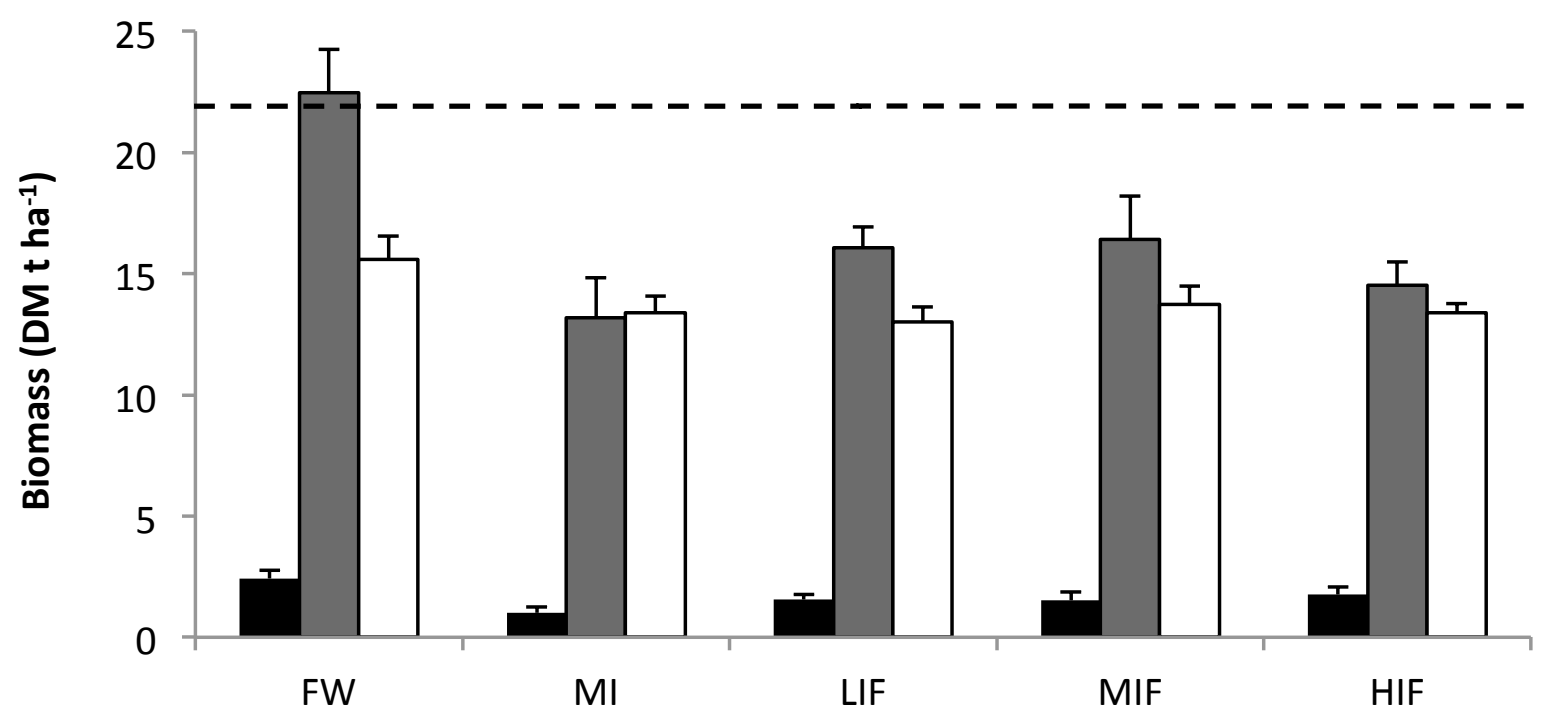

Figure 2 Biomass of willows (Salix reichardtii) harvested each year in each treatment block. Black bars are the first winter stem only harvest (June 2009), grey bars are the second autumn stem and leaf harvest (April 2010) and open bars are the third autumn stem and leaf harvest (April 2011). Treatment groups are fresh water, drip-irrigated (FW), reclaimed water, flood irrigated at medium rate with no mid-winter flush (MI), low (LIF), medium (MIF) and high flood irrigation rate with a mid-winter flush irrigation (HIF). The dotted line represents third season biomass produced by freshwater irrigated $S$. reichardtii growing in biosolids recorded by Laidlaw et al. (2012) in 2008. Statistical tests of differences between treatments are listed in Table 1. Error bars are standard error of the mean.

The salinity of the biosolids irrigated with freshwater was significantly less than the lagoon water irrigated biosolids in season 1 and season 3 (Table 1, Fig. 1). The changes over the trial period in the acidity and the salinity of the flood-irrigated biosolids $(0-10 \mathrm{~cm})$ also occurred at depth down the biosolids profile (Table 2). At the end of the trial the salinity of the nonirrigated biosolids (NI) had decreased in the surface layer but remained high below $10 \mathrm{~cm}$ depth (Table 2). The total concentrations and magnesium chloride extractable concentrations of $\mathrm{Cd}, \mathrm{Cu}, \mathrm{Ni}$ and $\mathrm{Zn}$ in non-irrigated biosolids (NI) sampled in 2009 and in 2011 are shown in Table 3. The extractable fractions of $\mathrm{Cd}, \mathrm{Ni}$ and $\mathrm{Zn}$ in the biosolids represented more than a third of the total concentrations of these heavy metals. The extractable fraction for $\mathrm{Cu}$ was $<$ 
$4 \%$ of the total concentration in the biosolids. The total concentration of $\mathrm{Cd}$ and $\mathrm{Cu}$ did not change between 2009 and 2011. However, the total concentration of $\mathrm{Ni}$ and $\mathrm{Zn}$ and the concentrations of all exchangeable fractions of all heavy metals was significantly reduced in 2011 compared to 2009. The electrical conductivity also decreased in the biosolids and the $\mathrm{pH}$ increased slightly, but significantly.

a)

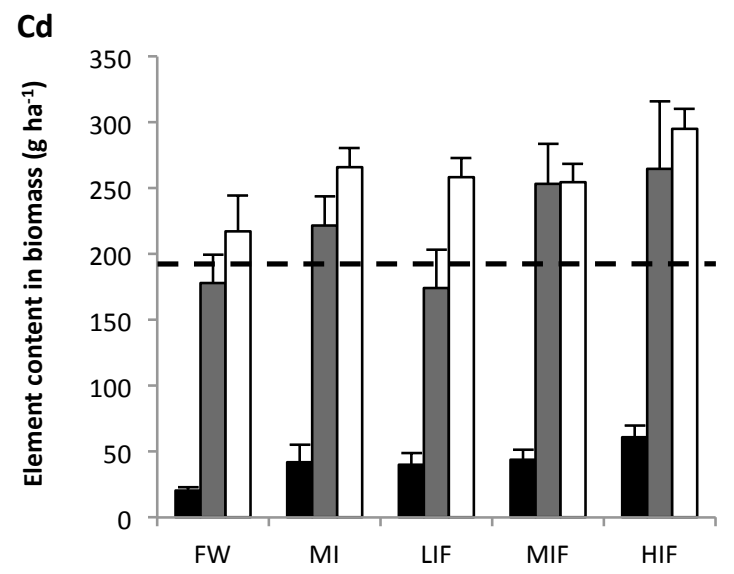

c)

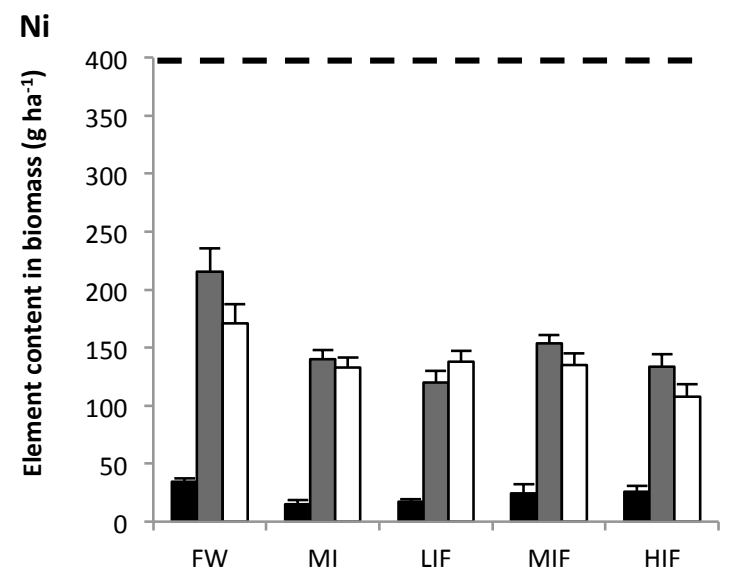

b)

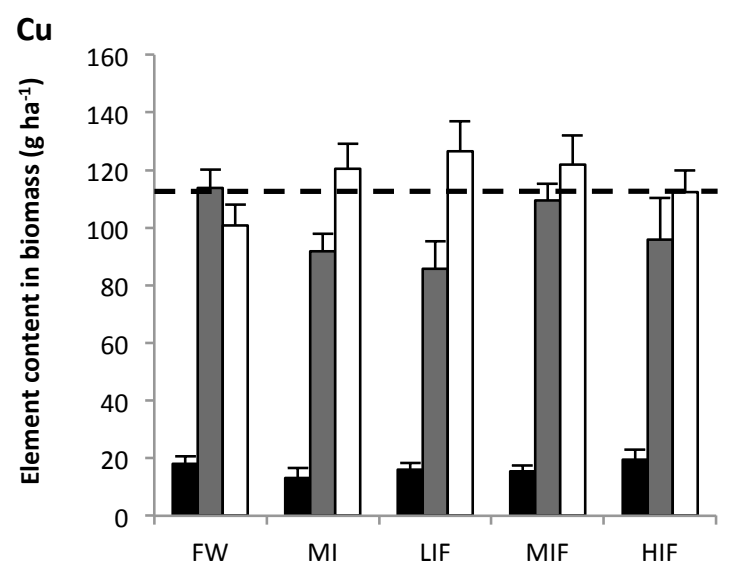

d)

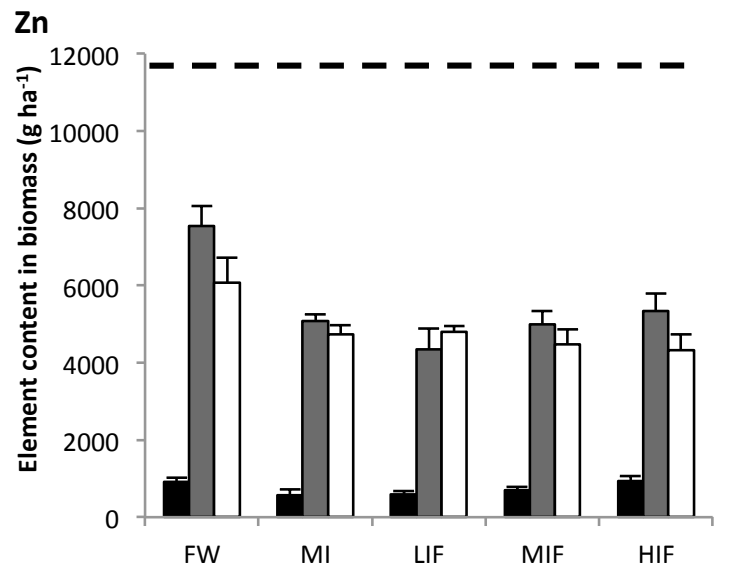

Figure 3 Cadmium (a), Copper (b), Nickel (c) and Zinc (d) extracted from biosolids (gm ha-1) in the annually harvested biomass. Black bars - autumn 2009, grey bars - autumn 2010, open bars - autumn 2011. Treatment groups are fresh water, drip-irrigated (FW), reclaimed water, flood irrigated at medium rate with no mid-winter flush (MI), low (LIF), medium (MIF) and high flood irrigation rate with a mid-winter flush irrigation (HIF). Dotted line represents level of metal extraction recorded by Laidlaw et al. (2012). Error bars are standard error of the mean. 


\subsection{Reclaimed water vs freshwater}

Willows irrigated with freshwater produced significantly more biomass compared to willows irrigated with reclaimed water in the second year (Fig. 2, Table 1) and this biomass production was similar to that produced in previous experiments at the site. The biomass production was smaller in the third year and similar to that of the reclaimed water treatments. The mass of $\mathrm{Cu}, \mathrm{Ni}$ and $\mathrm{Zn}$ extracted by the willow harvest was significantly higher in the freshwater irrigated willows in the second harvest but not the third harvest (Fig. 3, Table 3). Cadmium extraction was not significantly different between the water treatments in any of the seasons (Fig. 3).

\subsection{Winter flushing vs no flushing}

The willow biomass produced in the block receiving the winter flushing treatment was significantly greater in the second season compared to no flush (this is comparing treatments MI and MIF) but there was no difference observed between treatments in the third season (Fig. 2, Table 1). The mass $\left(\mathrm{kg} \mathrm{ha}^{-1}\right)$ of $\mathrm{Cd}, \mathrm{Cu}, \mathrm{Ni}$ and $\mathrm{Zn}$ removed in the harvests each year from the winter-flushed block was the same as the unflushed treatment block (Fig. 3, Table 3). There was a significant difference in the acidity of the biosolids between the winterflushed treatment and the unflushed treatment in the third season (Table 1) and the salinity of the winter-flushed treatment was higher than the unflushed treatment in the second season (Table 1, Fig. 1). The salinity of the water draining out from the biosolids during the winterflushed irrigation treatment was in general greater than the inflowing reclaimed water flushed through the blocks (supplementary data).

\subsection{Reclaimed water irrigation rate}

Irrigating the willows with reclaimed water at three different rates produced no statistically significant differences in biomass production (Fig. 2, Table 1). Similarly, there 
was no statistically significant difference in the mass of metals extracted by the biomass harvest between the three irrigation rates (Fig. 3, Table 1).

\section{Discussion}

This is the first study to investigate the impact of water quality and quantity of irrigation on metal extraction of willows growing in biosolids. Our data clearly demonstrate that and irrigation-based willow phytoextraction system is effective in extracting multiple metals from biosolids. However, our data also highlight that irrigation does impact on the metal extraction efficiency by changing biosolid attributes.

The biosolids at the trial site were moderately saline and several willow varieties can tolerate moderately to severe saline soils (Hangs et al., 2011). However, saline soils can constrain plant growth through water deficiency, ion toxicity and nutrient imbalance (Shabala and Munns, 2012). Irrigation can supplement natural precipitation particularly in a low rainfall, high evaporation climate, alleviating water deficiency, enhancing the establishment of cuttings or seedlings and growth of the trees in successive seasons. Previous trials using willows at this site have demonstrated that irrigation was essential in order to successfully establish and support the growth of willows in biosolids (Laidlaw et al., 2012). South-eastern Australia had experienced drought or near drought conditions for several years prior to this trial. Annual evaporation at the WTP is $1300-1400 \mathrm{~mm}$ and annual rainfall $400-500 \mathrm{~mm}$ (Bureau of Meteorology, 2012). In this context the planned rate of irrigation was generous with the aim to discover if the maximum annual biomass production from a willow shortrotation crop plantation could be increased with additional available water. Increasing irrigation rates, however, produced no differences in total biomass and also no differences in the extraction of heavy metals. The lowest irrigation rate provided sufficient additional water and there was thus no benefit from higher rates of irrigation. 
Biosolids contain a large amount of organic matter. The application of additional organic matter in agricultural systems is generally regarded as beneficial as it increases microbial density and also provides nutrients and readily degradable organic matter (Masciandaro et al., 2013). The application of organic amendments in situ has been used to reduce metal bioavailability of soils (Zubillaga et al., 2012). However, the biosolids in the current study already contained large and variable amounts of heavy metal contaminants, some of which were bioavailable and others that were predominantly bounds to $\mathrm{Fe} / \mathrm{Mn}$ oxides (Laidlaw et al., 2012). Previous studies indicated that the extractability of many heavy metals $(\mathrm{Cd}, \mathrm{Cr}, \mathrm{Cu}, \mathrm{Ni}, \mathrm{Zn})$ in these biosolids depended on their bioavailability (Laidlaw et al., 2012). The bioavailability can be influenced by the presence of plants. In a column study using biosolids and willow and poplar the presence of plants affected the $\mathrm{Cd}, \mathrm{Ni}$, and $\mathrm{Zn}$ pools (soluble/exchangeable; Fe/Mn oxide and organic matter bound) but did not reduce the total metals in either substrate. However, plants had no effect on $\mathrm{Cu}$, presumably because of the effective buffering of available $\mathrm{Cu}$ by organic matter in both solution and solid phases (Huynh et al., 2012).

Biomass production can influence the efficiency of phytoextraction of metals. Metal accumulating plants with high biomass production and moderate metal uptake can extract more metals than plants with higher metal uptake and less biomass production (Mok et al., 2013). Previous trials at the study site demonstrated that annually harvested willow plantations had the highest annual biomass production in year 3 however this was not observed in this trial. In the second year of the trial, reclaimed water irrigated willows produced a similar biomass to a previous freshwater irrigated field trial $\left(18 \mathrm{tha}^{-1} \mathrm{yr}^{-1}\right)$. In the third year, however, all blocks produced between 13 and $16 \mathrm{t} \mathrm{ha}^{-1} \mathrm{yr}^{-1}$, which was much less than 20-25 $\mathrm{t} \mathrm{ha}^{-1} \mathrm{yr}^{-1}$ expected from a 3 year old plantation (Laidlaw et al., 2012). This unexpected decrease appears to be linked to changes in local climate at the field site. In the 
first two years the site experienced above average evaporation and below average rainfall. However, in the third growing season (2010/2011) the field site experienced double the average rainfall and lower than average temperatures. The first two months and the last two months of the $3^{\text {rd }}$ year growing season were cooler than previous years. Salix in general is tolerant to water-logging and the excess rainfall is unlikely to have been the primary influence limiting growth. Lower than usual temperatures in early spring may have delayed budburst and de-hardening (Lennartsson and Ögren, 2004) leading to slower initial growth and a shortening of the growing season length. Our data highlight that local and annual variations in climate over the long term have an impact and actual remediation lifecycles may be significantly larger or smaller than estimated from the third year of plantation growth.

Alongside the benefits of supplemental irrigation, the reclaimed water produced changes in the chemistry of the biosolids. The reclaimed water reduced both the salinity and the acidity of the biosolids significantly within the first 12 months after irrigation commenced and after three seasons the salinity of the biosolids had dropped to $<15 \%$ of initial values. Non-irrigated biosolids also exhibited a reduction in salinity suggesting that the aboveaverage rainfall and high rainfall events in the 2010/2011 season contributed to a reduction in the salinity of the surface biosolids in all treatment groups. This reduction in salinity, however, did not extend beyond the top $10 \mathrm{~cm}$ layer of biosolids in non-irrigated biosolids.

At the commencement of the field trial the biosolids were acidic $(\mathrm{pH}<4.7)$ and irrigation with the slightly alkaline reclaimed water raised the $\mathrm{pH}>5.5$ by the end of the first growing season. Unexpectedly, the $\mathrm{pH}$ of the freshwater irrigated biosolids in this study increased to above 5. In previous trials irrigation with freshwater had little impact on acidity and these biosolids remained acidic $(\mathrm{pH}<5)($ Laidlaw et al. 2012). It is possible that reclaimed water from the adjacent block leaked through the earth check bank into the freshwater block raising the $\mathrm{pH}$ more than expected. 
In the short timeframe of this trial the use of reclaimed water did not result in salinization of the biosolids; in fact, the opposite occurred with salinity decreasing over the first 12 months. Flushing the plantation blocks with reclaimed water during winter followed by draining did remove some water-soluble elements as shown by the increased conductivity of the drain water. We suspect the majority of the soluble elements have leached downward through the soil profile as biosolids salinity had decreased at the end of the first growing season before the first winter flushing treatment was applied. Future studies should investigate this in more detail as salinization of the subsoil can have detrimental consequences for plant growth in the long-term. In addition the winter flushing did not decrease salinity below the no-flush treatment. This suggests that when coupled with the irrigation rates used in this trial the application of a flushing treatment is unnecessary in the short term.

Metal extraction from biosolids is a product of willow biomass production and the concentration of metals in the plant material (Greger and Landberg, 1999; Mok et al., 2013). Irrigating with freshwater enhanced biomass production and metal extraction in year two compared to willows irrigated with reclaimed water, however, this benefit disappeared in the third year. From the perspective of maximising phytoextraction efficiency the use of freshwater irrigation might be indicated but freshwater is a limited resource and its use at an industrial scale is unsustainable. The alternative, irrigation with reclaimed water supported biomass production also brought about potential changes in metal availability. The application of reclaimed water raised the $\mathrm{pH}$ of the biosolids and changes in $\mathrm{pH}$ can influence the bioavailability of heavy metals. When soil $\mathrm{pH}$ becomes acid, the bioavailability of cations generally increases due to replacement of cations on soil cation exchange capacity sites by $\mathrm{H}^{+}$ ions. For example, by lowering the soil $\mathrm{pH}$, the adsorption of $\mathrm{Zn}$ is reduced, resulting in the mobilization and potentially leaching of $\mathrm{Zn}$ (Pinto et al., 2014). Conversely, if the pH increases the bioavailability of heavy metals often decreases. In our study we did not directly 
investigate the bioavailability of metals in the biosolids but we noticed differences in the metal extraction by plants between treatments and compared to previous studies. We observed a significantly reduced phytoextraction of $\mathrm{Ni}$ and $\mathrm{Zn}$ by the willows compared to previous results (Laidlaw et al., 2012). Nickel and Zn extraction was highest in the freshwater irrigation treatment in the second season when the $\mathrm{pH}$ of the biosolids was lowest. On the other hand we did not observe any treatment differences for $\mathrm{Cu}$ and extraction rates were similar to those previously reported for the site, whilst $\mathrm{Cd}$ extraction was greatest in the reclaimed water treatments and also greater than previously reported (Laidlaw et al., 2012). It is possible that the addition of excess chloride ions present in reclaimed water to the biosolids could favour the formation of the more bioavailable $\mathrm{CdCl}^{+}$thus in term increasing $\mathrm{Cd}$ uptake by willows. These changes in metal extraction rates were not only related to changes in biomass production, and this indicates that different metals potentially respond differently to changes in the biosolid properties.

It is also possible that the irrigation with reclaimed water in combination with the high rainfall led to a leaching of certain metals and therefore a reduced bioavailability. We only investigated metal concentrations in the non-irrigated biosolids prior and after the irrigation experiment, but in these biosolids we observed a decrease in the total concentration of $\mathrm{Ni}$ and $\mathrm{Zn}$ and a decrease in the concentration of the extractable fraction of all metals. The decrease in the total $\mathrm{Ni}$ and $\mathrm{Zn}$ concentration corresponds with the lower extraction of these metals by plant biomass. If the unusually high rainfall during some of our study years led to the decrease in the concentration of non-irrigated biosolids then the additional irrigation treatment could have led to even greater leaching and limited extraction for some metals. Some studies have shown that the migration of heavy metals in soils can be negligible other studies have demonstrated that significant amounts of $\mathrm{Zn}, \mathrm{Cr}, \mathrm{Cu}$ and $\mathrm{Cd}$ (among others) were readily leached (Karathanasis et al., 2005; Toribio and Romanya, 2006). After 14 years of 
massive sludge additions only small amounts of sludge-borne Cd and $\mathrm{Zn}$ moved out of the tillage zone into the subsoil of a highly structured agricultural soil, while no increases in $\mathrm{Cu}$ levels were observed (Dowdy et al., 1991). Similarly, in a clay loam soil where biosolids were applied 17 years earlier there was negligible movement of trace metals through the soil profile and more than $95 \%$ of $\mathrm{Cu}, \mathrm{Ni}$ and $\mathrm{Zn}$ were accounted for with mass balance calculations that also included plant uptake and soil removal (Sukkariya et al., 2005). Conversely, in forest soils that were treated with heavy metal contaminated sewage sludge a differential mobility of metals was observed: Ni exhibited the greatest mobility, Zn mobility was also rather high, particularly in the acid soil, whereas $\mathrm{Cu}$ was barely mobile (Toribio and Romanya, 2006). In a study on the effects of plants on the solution phase of aged biosolids over 12 months in a column experiment, plants temporarily decreased solution phase $\mathrm{pH}$ during the fast growth period in summer followed by a return to the initial $\mathrm{pH}$. Plants only significantly affected metal concentrations in the solution phase at the $15 \mathrm{~cm}$ depth and metals were leached down to the lower depth of the columns (Huynh et al., 2008). These results and our own observation indicate that the influence of irrigation amount and water quality on heavy metal bioavailability and solubility needs to be studied in more detail. If metals are leached from biosolids through excessive rainfall and/or irrigation then this can lead to contamination of soil layers further down the profile.

\section{Conclusions}

This field trial has demonstrated that flood irrigation of water reclaimed from a wastewater treatment facility can be used to support the establishment and growth of willows in metal-contaminated biosolids. The amount of flood irrigation had no impact on the biomass production and metal extraction of the willows both in normal dry years (year 2) or unusually wet years (year 3). Hence, as long as there is sufficient water willows will grow and extract 
metals. The quality of irrigation water had some impact on biomass growth and also metal extraction. Fresh water irrigated plants grew better in a dry year (year 2) and extracted more metals. However, in a wet year these differences were not apparent. This indicates that slightly saline reclaimed water can marginally reduce biomass growth in willows. However, our results clearly indicate that irrigation does have an impact on biosolids attributes such as salinity and $\mathrm{pH}$, and that this can have an influence on metal extraction. Irrigation with reclaimed water increased biosolid $\mathrm{pH}$ and this was associated with the reduction of the extraction of $\mathrm{Ni}$ and $\mathrm{Zn}$, it did not influence the extraction of $\mathrm{Cu}$ and the high chloride content of the reclaimed water enhanced the phytoextraction of $\mathrm{Cd}$. The effect of irrigation with reclaimed water on the potential leaching of metals in biosolids needs further investigation. Seasonal variations in climate, particularly temperature, can have significant impacts on plantation growth and in turn on the efficiency of the overall metal removal by a long-term phytoextraction system.

\section{Acknowledgements}

This project was funded by the Australian Research Council Linkage Program (LP0883573) in partnership with the Melbourne Water Corporation and the University of Melbourne. We would like to thank the late Kurt Cremer, for generously providing the initial cuttings of Salix x reichardtii used in the field trials. Many thanks to Kevin Gillett, our 'go to' person at the Western Treatment Plant, Howard Nichols, John Couper and his crew for organising the preparation, infrastructure and maintenance at the field site. Thanks also to Kerryn Popa, Yaodong Wang, Anthony Fernando, Denise Fernando, Steve Elefteriadis, Blaire Dobiecki, Lee Hudek, Wes Webster, Geraldo Guimares, Skye Shields, Ramaprasad Majumder, Tonatiuh Sanchez Palacios, Seyedeh Mahdieh Sharafi, Julia Beyer, Dinagaran 
Chandra Saikharan and Reg D’Souza who helped out planting, weeding, watering, harvesting the willows or preparing samples for analysis.

\section{References}

Ahmed, B., Yamamoto, T., Inoue, M., 2007. Impact of leaching on sustainability of Sorghum on dune sand under saline drip irrigation water. Transactions of the ASABE 50, 1279-1286.

Ali, H., Khan, E., Sajad, M.A., 2013. Phytoremediation of heavy metals - concepts and applications. Chemosphere 91, 869-881.

Baker, A.J.M., 1981. Accumulators and excluders - strategies in the response of plants to heavy metals. Journal of Plant Nutrition 3, 643-654.

Baker, A.J.M., Brooks, R.R., 1989. Terrestrial higher plants which hyperaccumulate metallic elements - a review of their distribution, ecology and phytochemistry. Biorecovery 1, 81-126.

Brisolara, K.F., Qi, Y.A., 2013. Biosolids and sludge management. Water Environment Research 85, 1283-1297.

Bureau of Meteorology, 2012. Climate data online. Commonwealth of Australia.

Dimitriou, I., Eriksson, J., Adler, A., Aronsson, P., Verwijst, T., 2006. Fate of heavy metals after application of sewage sludge and wood-ash mixtures to short-rotation willow coppice. Environmental Pollution 142, 160-169.

Dowdy, R.H., Latterell, J.J., Hinesly, T.D., Grossman, R.B., Sullivan, D.L., 1991. Trace metal movement in an aeric ochraqualf following 14 years of annual sludge applications. Journal of Environmental Quality 20, 119-123.

EPA Victoria, 2003. Guidelines for environmental management. Use of reclaimed water. EPA Victoria, Australia.

EPA Victoria, 2004. Guidelines for environmental management. Biosolids land application. Environmental Protection Agency, Victoria, Melbourne. 
EPA Victoria, 2007. Increased levies for prescribed industrial waste. Environmental Protection Agency, Victoria, Melbourne.

Greger, M., Landberg, T., 1999. Use of willows in phytoextraction. International Journal of Phytoremediation 1, 115-123.

Hangs, R.D., Schoenau, J.J., Van Rees, K.C.J., Steppuhn, J., 2011. Examining the salt tolerance of willow (Salix spp.) bioenergy species for use on salt-affected agricultural lands. Canadian Journal of Plant Science 91, 509-517.

Huynh, T.T., Laidlaw, W.S., Singh, B., Gregory, D., Baker, A.J.M., 2008. Effects of phytoextraction on metal concentrations and $\mathrm{pH}$ of pore-water of biosolids determined using an in situ sampling technique. Environmental Pollution 156, 874-882.

Huynh, T.T., Laidlaw, W.S., Singh, B., Zhang, H., Baker, A.J.M., 2012. Effect of plants on the bioavailability of metals and other chemical properties of biosolids in a column study. International Journal of Phytoremediation 14, 878-893.

Huynh, T.T., Zhang, H., Laidlaw, W.S., Singh, B., Baker, A.J.M., 2010. Plant-induced changes in the bioavailability of metals in soil and biosolids assessed by DGT measurements. Journal of Soils and Sediments 10, 1131-1141.

Isebrands, J.G., Aronsson, P., Carlson, M., Ceulemans, R., Coleman, M., Dickinson, N.M., Dimitriou, J., Doty, S., Gardiner, E., Heinsoo, K., Johnson, J.D., Koo, Y.B., Kort, J., Kuzovkina, J., Licht, L., McCracken, A.R., McIvor, I., Mertens, P., Perttu, K., Riddell-Black, D., Robinson, B., Scarascia-Mugnozza, G., Schroeder, W.R., Stanturf, J., Volk, T.A., Weih, M., 2014. Environmental applications of poplars and willows, in: Isebrands, J.G., Richardson, J. (Eds.), Poplars and willows: trees for society and the environment. CABI Publishing, Wallingford, UK, pp. 258-336.

Karathanasis, A.D., Johnson, D.M.C., Matocha, C.J., 2005. Biosolid colloid mediated transport of copper, zinc and lead in waste-amended soils. Journal of Environmental Quality $34,1153-1164$. 
Kim, K.R., Owens, G., 2010. Potential for enhanced phytoremediation of landfills using biosolids - a review. Journal of Environmental Management 91, 791-797.

Laidlaw, W.S., Arndt, S.K., Huynh, T.T., Gregory, D., Baker, A.J.M., 2012. Phytoextraction of heavy metals by willows growing in biosolids under field conditions. Journal of Environmental Quality 41, 134-143.

Lennartsson, M., Ögren, E., 2004. Clonal variation in temperature requirements for budburst and dehardening in Salix species used for biomass production. Scandinavian Journal of Forest Research 19, 295-302.

Livesley, S.J., Kiese, R., Miehle, P., Weston, C.J., Butterbach-Bahl, K., Arndt, S.K., 2009. Soil-atmosphere exchange of greenhouse gases in a Eucalyptus marginata woodland, a clover-grass pasture, and Pinus radiata and Eucalyptus globulus plantations. Global Change Biology 15, 425-440.

Masciandaro, G., Macci, C., Peruzzi, E., Caeccanti, B., Doni, S., 2013. Organic mattermicroorganism-plant in soil bioremediation: a synergic approach. Reviews in Environmental Science and Bio/Technology 12, 399-419.

McLaughlin, M.J., Warne, M.S., Stevens, D.P., Whatmuff, M.S., Heemsbergen, D., Broos, K., Barry, G., Bell, M.J., Nash, D., Pritchard, D., Penney, N., 2007. Australia's National Biosolid Research Program - how it came about, and what has it discovered? Water Practice and Technology 2, Art 88.

Mok, H.F., Majumder, R., Laidlaw, W.S., Gregory, D., Baker, A.J.M., Arndt, S.K., 2013. Native Australian species are effective in extracting multiple heavy metals from biosolids. International Journal of Phytoremediation 15, 615-632.

Pilon-Smits, E.A.H., Freeman, J.L., 2006. Environmental cleanup using plants: biotechnical advances and ecological considerations. Frontiers of Ecology and the Environment 4, 203 210. 
Pinto, E., Aguiar, A.A.R.M., Ferreira, I.M.P.L.V.O., 2014. Influence of soil chemistry and plant physiology in the phytoremediation of $\mathrm{Cu}, \mathrm{Mn}$, and $\mathrm{Zn}$. Critical Reviews in Plant Sciences 33, 351-373.

Pulford, I.D., Dickinson, N.M., 2006. Phytoremediation technologies using trees, in: Prasad, M.N.V., Sajwan, K.S., Naidu, R. (Eds.), Trace elements in the environment: biogeochemistry, biochemistry, and bioremediation. CRC Press, Boca Raton, pp. 383-402.

Rascio, N., Navari-Izzo, F., 2011. Heavy metal hyperaccumulating plants: How and why do they do it? And what makes them so interesting? Plant Science 180, 169-181.

Shabala, S., Munns, R., 2012. Salinity stress: physiological constraints and adaptive mechanisms, Plant Stress Physiology. CABI Publishing, Wallingsford, UK, pp. 59-93.

Sukkariya, B.F., Evanylo, G., Zelazny, L., Chaney, R.L., 2005. Recovery and distribution of biosolids-derived trace metals in a clay loam soil. Journal of Environmental Quality 34, 18341850

Toribio, M., Romanya, J., 2006. Leaching of heavy metals (Cu, Ni and $\mathrm{Zn})$ and organic matter after sewage sludge application to Mediterranean forest soils. Science of the Total Environment 363, 11-21.

Van Nevel, L., Mertens, J., Oorts, K., Verheyen, K., 2007. Phytoextraction of metals from soils: How far from practice? Environmental Pollution 150, 34-40.

Zubillaga, M.S., Bressan, E., Lavado, R.S., 2012. Effects of phytoremediation and application of organic amendment on the mobility of heavy metals in a polluted soil profile. International Journal of Phytoremediation 14, 212-220. 